\title{
A model study of the wind stress influence on the interannual variability of the Antarctic Circumpolar Current
}

\author{
K. V. Lebedev ${ }^{1}$ and R. Yu. Tarakanov ${ }^{1}$ \\ Received 30 November 2017; accepted 6 December 2017; published 7 March 2018.
}

The interannual variability of the Antarctic Circumpolar Current (ACC) transport in the Drake Passage is studied on the basis of simulations performed using the Argo-based model for Investigation of the Global Ocean (AMIGO), which consists of a block for variational interpolation of the Argo floats data to a regular grid and a block for model hydrodynamic adjustment of variationally interpolated fields. Such a technique allows us to obtain a complete set of oceanographic characteristics from irregularly located Argo measurements: temperature, salinity, density, and current velocity. The calculation results are presented as monthly, seasonal, and annual means and climatological fields. The mean ACC transport through the Drake Passage in 2005-2014 was estimated at $162 \pm 5 \mathrm{~Sv}\left(1 \mathrm{~Sv}=10^{6} \mathrm{~m}^{3} \mathrm{~s}^{-1}\right)$. Two additional numerical experiments were carried out in order to study the contribution of the wind forcing to the interannual variability of the ACC transport: the real thermohaline fields corresponding to the particular time period were replaced by climatic ones (Experiment 1); the real wind forcing data were replaced by the climatic ones (Experiment 2). Analysis of the results of numerical experiments has shown that variable wind stress forcing is the key factor controlling the interannual variability of the ACC transport through the Drake Passage. KEYWORDS: Antarctic Circumpolar Current; transport; variability; modeling; Argo floats.

Citation: Lebedev, K. V. and R. Yu. Tarakanov (2018), A model study of the wind stress influence on the interannual variability of the Antarctic Circumpolar Current, Russ. J. Earth. Sci., 18, ES2002, doi:10.2205/2017ES000610.

\section{Introduction}

The most powerful current in the World Ocean is the Antarctic Circumpolar Current (ACC), which encircles Antarctica from west to east. The Drake Passage is the only area of the Antarctic where

\footnotetext{
${ }^{1}$ Shirshov Institute of Oceanology, Russian Academy of Sciences, Moscow, Russia

Copyright 2018 by the Geophysical Center RAS. http://rjes.wdcb.ru/doi/2017ES000610-res.html
}

the ACC extends from one continental slope to another (Figure 1). This fact determines the applicability of this region to obtain reliable estimates of the ACC transport. According to the classical concepts, the ACC geostrophic flow extends from the sea surface almost to the bottom. However, the analysis of hydrographic data shows that in the Drake Passage the current is limited to the depths of 2000-2500 $\mathrm{m}$ in its axial part (near the Polar Front) and up to the depths of 1000-1500 m at the northern and southern peripheries of the current [Tarakanov, 2012]. At depths below the ACC a 


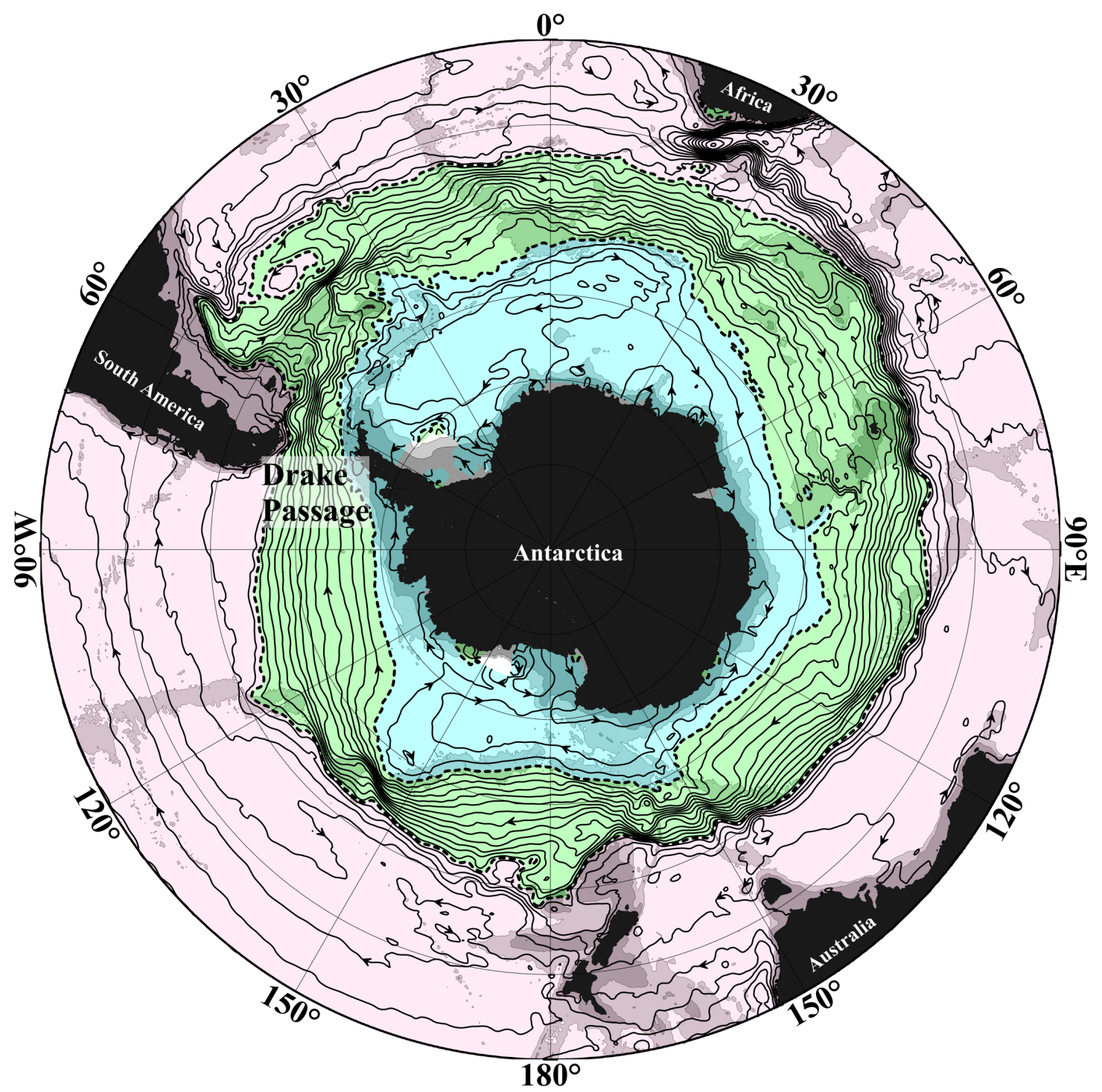

Figure 1. Mean dynamic topography CNES-CLS09 [Rio et al., 2011]. The region of closed streamlines of the geostrophic current corresponding to the Antarctic Circumpolar Current is shown with the green color.

very intense (but with a near-zero total transport) abyssal circulation is formed, which is controlled by strongly-dissected bottom topography [Koshlyakov et al., 2013, Tarakanov, 2012. The near-zero balance of the bottom circulation in the Drake Passage means that any total cross-section transport corresponds to the total ACC transport through the passage.

The available quasi-simultaneous estimates of the Drake Passage transport are made using geostrophic calculations based on hydrographic section data and a barotropic correction calculated using either the direct Acoustic Doppler Current Profiler measurements (lowered or shipboard) of the current ve- locities [Cunningham et al., 2003. Gladyshev et al., 2008, Koshlyakov et al., 2010, 2011, 2012, 2013, Renault et al., 2011, or Absolute Dynamic Topography (ADT) derived from the satellite altimetry data [Koshlyakov et al., 2007]. These transport estimates widely range from 100 to $185 \mathrm{~Sv}$ $\left(1 \mathrm{~Sv}=10^{6} \mathrm{~m}^{3} \mathrm{~s}^{-1}\right)$.

The first estimates of the total transport through the Drake Passage dated back to the early 1980s were based on a year-long moored time series of currents accompanied by the hydrographic data sections [Whitworth, 1983; Whitworth and Peterson, 1985. According to these studies, the total transport through the passage is $134 \pm 11 \mathrm{~Sv}$. How- 
ever, even these authors note that this value is underestimated because of the insufficient data coverage in the regions of submarine slopes of the passage. Recently, a total transport of $173 \pm 11 \mathrm{~Sv}$ was estimated on the basis of measurements in 2007-2011 on an array of more than 20 moorings across the Drake Passage [Donohue et al., 2016. The long-term (1993-2012) variability of the three flow components across the passage (total, barotropic, and baroclinic) with a reference level of $3000 \mathrm{~m}$ was analyzed from satellite altimetry observations along one of the tracks in the Drake Passage [Koenig et al., 2016; the corresponding transports were estimated at $140 \pm 10,28 \pm 13$, and $112 \pm 7 \mathrm{~Sv}$. It should be noted that all of the above estimates of the total transport through the Drake Passage are based on relatively short-term (up to a few years) or even episodic direct current observations.

The development of a global array of free-drifting profiling floats in the beginning of the 21st century (known as the international Argo Program) provides oceanographic community with the unique opportunity to continuously monitor the Southern Ocean and the ACC transport. Starting from 2005, measurements with the Argo floats have been performed over the major part of the World Ocean: today up to 3800 active floats autonomously profile the upper $2000-\mathrm{m}$ of the ocean with a 10-day interval. The Argo-based model for Investigation of the Global Ocean (AMIGO), developed at the Shirshov Institute of Oceanology of the Russian Academy of Sciences (SIO RAS), makes it possible to obtain a complete set of oceanographic characteristics: temperature, salinity, density and current velocity from irregularly located Argo measurements [Lebedev, 2016].

This work continues the authors' studies of the role of wind stress in the formation of the largescale oceanic circulation [Ivanov and Lebedev, 2003 and its variability [Ivanov and Lebedev, 1996, 2003]. As it was shown in the previous studies [ Ivanov and Lebedev, 1996, 2003, the variability of currents and, correspondingly, their transports are generally determined by non-stationary wind forcing at the ocean surface. The main goal of this research is to estimate the seasonal and interannual variability of the ACC transport on the basis of the AMIGO simulation results, and to study the role that wind forcing might play in the variability of the ACC transport.

\section{Data and Methods}

The study of the ACC transport variability is performed using the AMIGO simulations [Lebedev, 2016], based on Argo floats data [Argo, 2000 and ECMWF ERA-Interim reanalysis wind stress [Dee et al., 2011]. The model consists of a block for variational interpolation to a regular grid of irregularly distributed Argo data [Kurnosova and Lebedev, 2014, Lebedev et al., 2010 and a block for model hydrodynamic adjustment of variationally interpolated fields [Ivanov et al., 1997, Lebedev, 1999. The maps of ADT data (http://www.aviso.altimetry.fr/duacs/) derived from the Aviso satellite altimetry [Ducet et al., 2000] averaged over the corresponding time interval were used to control and verify the solution when selecting the model parameters. The calculations cover the 10-year period from 2005 to 2014; the data are represented as 120 monthly, 40 seasonal, and 10 annual means with the one degree spatial resolution. The 10-year Argo climatology includes 12 months, 4 seasons, and climatic year. The comparison of model simulations with the drifter data revealed that temperature and salinity fields calculated using the Argo data and the variational interpolation on a regular grid restore realistic currents fields [Lebedev et al., 2016. Sarkisyan et al.,2016. The use of sea surface salinity (SSS) data, derived from the Argo measurements using the described above variational technique, improves the interannual variability of the mixed layer depth in the ocean general circulation models, also so-called "barrier layers" are reproduced when the Argo SSS is used [Furue et al., 2018. The AMIGO database is freely available in the Internet at the official SIO RAS server at http://argo.ocean.ru/.

Two additional numerical experiments were carried out in order to study the contribution of the wind forcing to the variability of the ACC transport. In Experiment 1, the temperature and salinity fields, used in the AMIGO calculations, were replaced by the climatic ones (the simulation for January 2005 was performed using January 20052014 AMIGO climatology and January 2005 wind stress data, and so forth). This allowed us to estimate the impact of the wind stress forcing on the ACC transport variability.

In Experiment 2, the wind stress data, used 


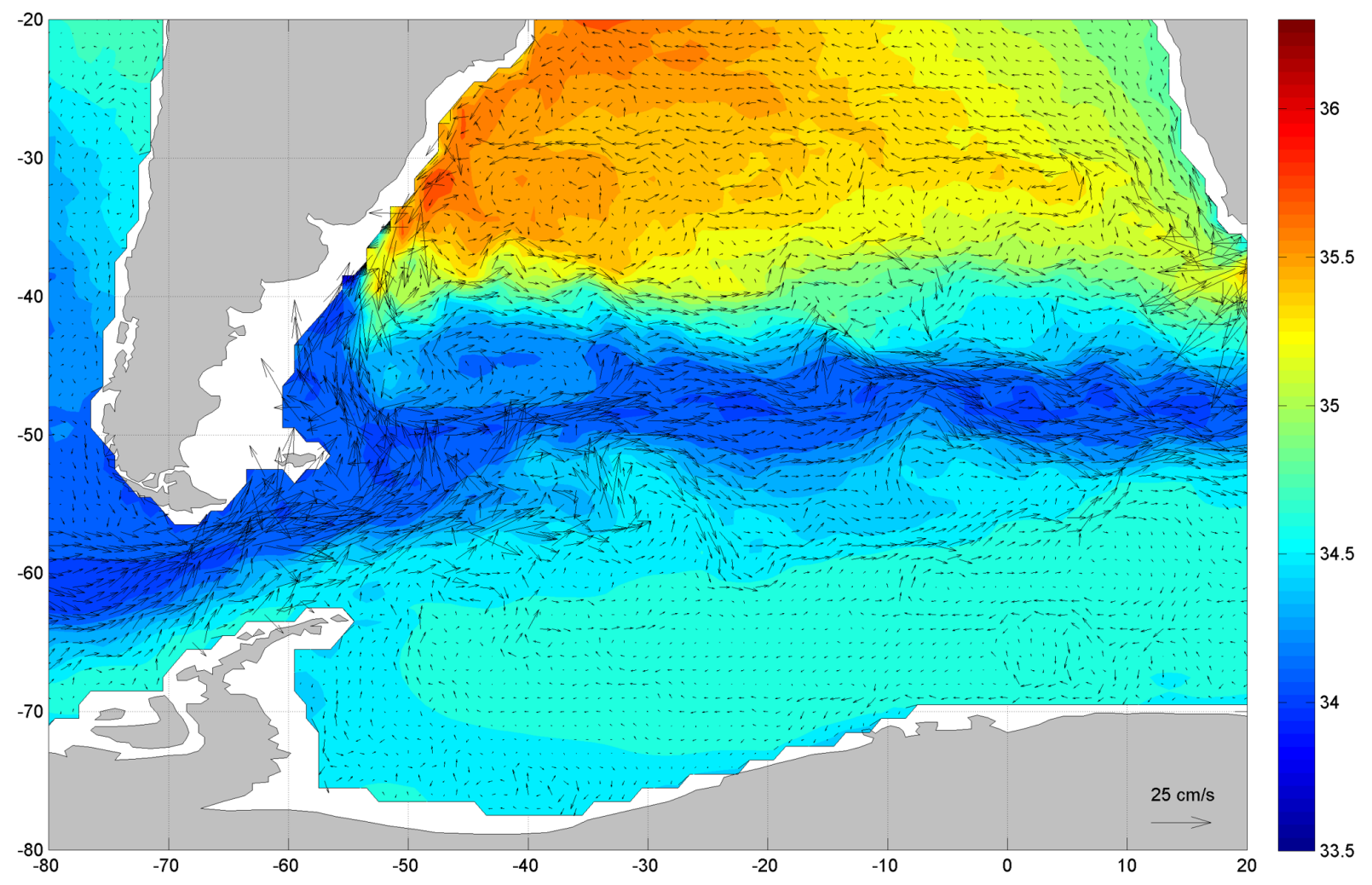

Figure 2. Maps of the annual mean velocities and salinity in the Atlantic sector of the Southern Ocean at $250 \mathrm{~m}$. Velocity scale is shown with an arrow. Salinity color scale is shown on the right.

in the AMIGO simulations, were replaced by the 2005-2014 climatic ones (the simulation for January 2005 was performed using January 2005 AMIGO temperature and salinity data and averaged over 2005-2014 January wind, and so forth). These calculations were aimed at estimating the contribution of the interannual thermohaline variability to the total ACC transport variability.

\section{Results}

A map of the AMIGO-based mean salinity and currents of the Atlantic sector of the Southern Ocean is shown in Figure 2, The West Wind Drift, Benguela, Brazil, and Falkland currents are well pronounced in the velocity field, as well as the northern and southern ACC branches. The ACC position can be reliably traced along the salinity minimum: the Subantarctic Front (SAAF), which is the northern boundary of the ACC, is clearly seen in the salinity field. North of the Falkland Is- lands, the SAAF forms a sharp loop-like meander as a result of the separation of the northward Falkland Current from the ACC in that region. The southern ACC boundary is also clearly seen: the salinity at this depth is minimal in the ACC area, and increases when approaching Antarctica due to the Circumpolar Deep Water upwelling in the Weddell Gyre.

The mean ACC transport over the period of 2005-2014 trough the Drake Passage based on the AMIGO monthly mean data was diagnosed as $162 \pm$ $5 \mathrm{~Sv}$. The maximum transport value equal to $173 \mathrm{~Sv}$ occurred in May 2006, the minimum value of $149 \mathrm{~Sv}$ was recorded in July 2007. The value of the mean ACC transport trough the Drake Passage is in a good agreement with the recent estimates of $173 \pm 11 \mathrm{~Sv}$ based on a large number of current observations in the passage [Donohue et al., 2016].

Intradecadal variability of the ACC transport through the Drake Passage is presented in Figure 3. The results of the AMIGO numerical simulations are shown by the blue solid line. The results of numerical Experiment 1 with replacement of the 


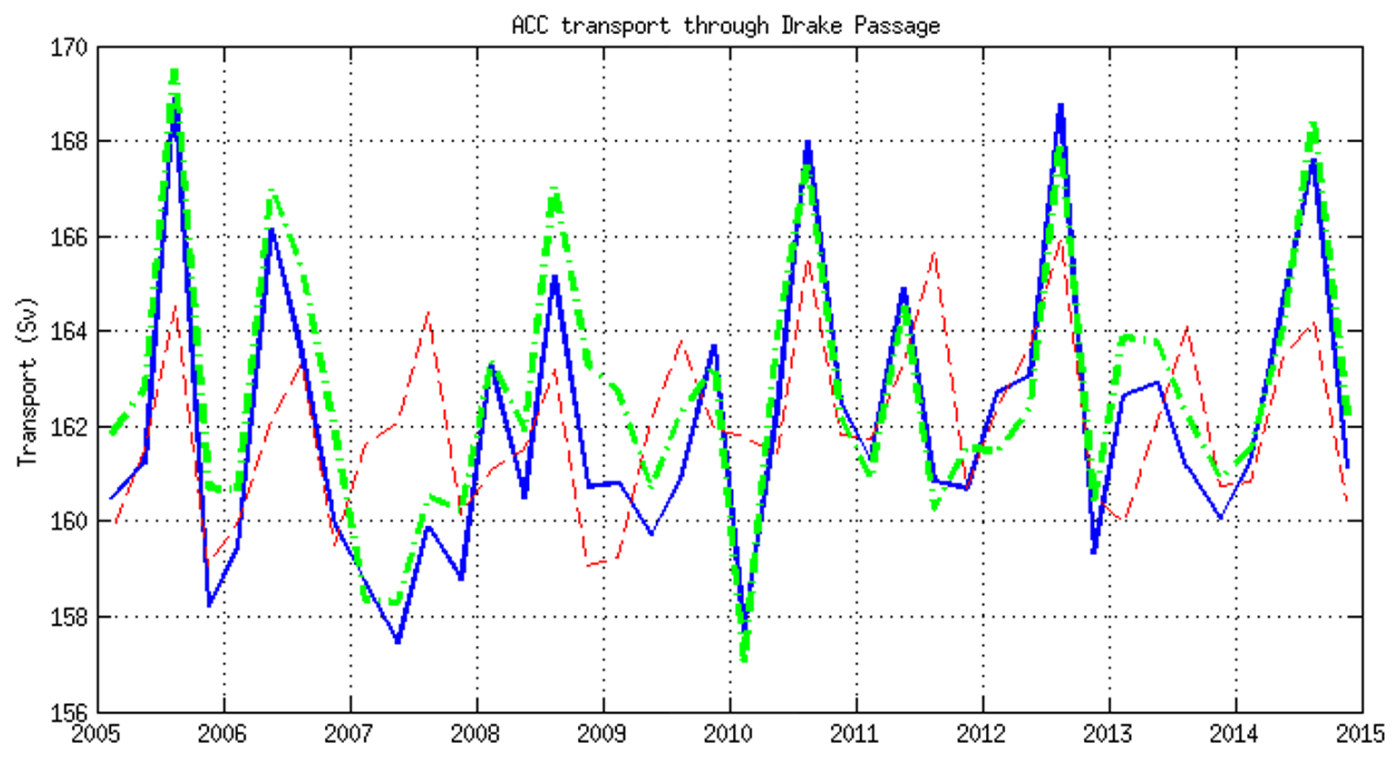

Figure 3. ACC transport $(\mathrm{Sv})$ through the Drake Passage calculated using AMIGO data (blue solid line), using Experiment 1 (green dash-dotted line), and Experiment 2 data (red dashed line). All the data are represented as seasonal values over the period of 2005-2014.

real temperature and salinity fields by the corresponding 2005-2014 climatic ones are represented by the green dash-dotted line. The thin red dashed line corresponds to the results of numerical Experiment 2 , in which the wind stress data for the corresponding seasons averaged over 2005-2014 were used instead of the real ones.

Analysis of the ACC transport variability in the Drake Passage based on the AMIGO data (blue solid line) shows that the transport variations do not exhibit notable seasonality, especially in the monthly mean data (not drawn): significant deviations occurred in 2007, 2009, 2011, and 2013. The maximum variability of the ACC seasonal mean transport was recorded in 2005, when the transport decreased from $169 \mathrm{~Sv}$ in austral winter to $158 \mathrm{~Sv}$ in spring. The interannual variability reaches $9 \mathrm{~Sv}$ in austral fall and winter and $6 \mathrm{~Sv}$ in austral spring and summer seasons. Low absolute values accompanied by the weak intraannual transport variability were recorded during the whole year in 2007 . In the following years, the maximum values of transport through the Drake Passage were observed in austral winter, while the minima occurred in austral spring and summer seasons.

The ACC transport variations in Experiment 1, in which the real seasonal wind was used with the climatic seasonal temperature and salinity data (green dash-dotted line), are very similar to the transport variations in the AMIGO simulations (blue solid line). The interannual variability values in this case are also very close to the AMIGO ones.

The transport variations in Experiment 2, in which the climatic wind for the corresponding season was used with the real seasonal temperature and salinity fields (red dashed line), remarkably differs from previous simulations, exhibiting well pronounced seasonality with an austral winter maximum and spring-summer minimum. Note, that the difference between the winter and summer transports in this case does not exceed $6 \mathrm{~Sv}$. The interannual variability is very weak and does not exceed $3 \mathrm{~Sv}$ : the minimum and maximum values of transports are 163 and $166 \mathrm{~Sv}$ in the austral winter and 159 and $162 \mathrm{~Sv}$ in the austral spring, respectively.

\section{Conclusions}

The following conclusions can be drawn from the results presented in the paper.

1. The AMIGO simulations based on the Argo data for the period of 2005-2014 allowed us to estimate the ACC transport and its variabil- 
ity in the Drake Passage. The ACC transport is diagnosed at $162 \pm 5 \mathrm{~Sv}$. The variations of ACC transport through the Drake Passage do not exhibit notable seasonality. The maximum value of the monthly mean transport was estimated at $173 \mathrm{~Sv}$ in May 2006, the minimum value of $149 \mathrm{~Sv}$ occurred in July 2007. The diagnosed mean ACC transport is in a good agreement with the recent estimates based on the current observations in the Drake Passage.

2. A numerical experiment with the replacement of the real seasonal wind stress data in the AMIGO simulations by the corresponding values averaged over the period of 20052014 showed that in this case the variability of the ACC transport in the Drake Passage exhibits strong seasonality, but the difference between the values of austral winter and summer transports noticeably decreases, and the interannual variability becomes weak. This result makes it possible to conclude that the Southern Ocean thermohaline interannual variability has only a slight effect on the variability of the total ACC transport through the Drake Passage.

3. A numerical experiment with the replacement of the real temperature and salinity fields in the AMIGO simulations by the corresponding climatic ones showed that in this case the variability of the ACC transport in the Drake Passage is very similar to the ACC transport variability observed in the original AMIGO simulations. Thus, we conclude that variable wind stress forcing is the key factor responsible for the interannual variability of the total ACC transport through the Drake Passage.

Acknowledgments. The Argo data were collected and made freely available by the International Argo Program and the national programs that contribute to it (http://www.argo.ucsd.edu, http://argo.jcommops.org). The Argo Program is part of the Global Ocean Observing System. The altimeter products were produced by Ssalto/Duacs and distributed by Aviso, with support from Cnes (http://www.aviso.altimetry.fr/duacs/). The work was supported by the Russian Science Foundation, grant 16-17-10149.

\section{References}

Argo (2000), Argo float data and metadata from Global Data Assembly Centre (Argo GDAC), SEANOE Crossref

Cunningham, S. A., S. G. Alderson, B. A. King, M. A. Brandon (2003), Transport and variability of the Antarctic Circumpolar Current in Drake Passage, J. Geophys. Res., 108, No. C5, 8084 Crossref

Dee, D. P., et al. (2011), The ERA-Interim reanalysis: Configuration and performance of the data assimilation system, Quart. J. R. Meteorol. Soc., 137, 553-597.Crossref

Donohue, K. A., et al. (2016), Mean Antarctic Circumpolar Current transport measured in Drake Passage, Geophys. Res. Lett., 43, 11,760-11,767 Crossref

Ducet, N., P. Y. Le Traon, G. Reverdin (2000), Global high-resolution mapping of ocean circulation from TOPEX/Poseidon and ERS-1 and 2, J. Geophys. Res., 105, No. C8, 19,477-19,498 Crossref

Furue, R., K. Takatama, H. Sasaki, N. Schneider, M. Nonaka, B. Taguchi (2018), Impacts of sea-surface salinity in an eddy-resolving semi-global OGCM, Ocean Modelling, 122, 36-56 Crossref

Gladyshev, S. V., et al. (2008), Currents in the Drake Passage based on observations in 2007, Oceanology, 48, 759-770 Crossref

Ivanov, Yu. A., K. V. Lebedev (1996), Numerical simulation of the North Atlantic response to a nonstationary wind forcing, Izvestiya, Atmospheric and Oceanic Physics, 32, 620-627.

Ivanov, Yu. A., K. V. Lebedev (2003), Model studies of the estimate of the contribution of wind-driven currents to the general circulation of the World Ocean, Oceanology, 43, 827-833.

Ivanov, Yu. A., K. V. Lebedev, A. S. Sarkisyan (1997), Generalized hydrodynamic adjustment method (GHDAM), Izvestiya, Atmospheric and Oceanic Phys., 33, $752-757$.

Koenig, Z., C. Provost, Y.-H. Park, R. Ferrari, N. Sennéchael (2016), Anatomy of the Antarctic Circumpolar Current volume transports through Drake Passage, J. Geophys. Res. Oceans, 121, 2572-2595 Crossref

Koshlyakov, M. N., I. I. Lisina, E. G. Morozov, R. Yu. Tarakanov (2007), Absolute geostrophic currents in the Drake Passage based on observations in 2003 and 2005, Oceanology, 47, 451-463.Crossref

Koshlyakov, M. N., S. V. Gladyshev, R. Yu. Tarakanov, N. I. Ryzhikov (2010), Deep currents in the central part of the Drake Passage based on the data of the 2008 hydrographic survey, Oceanology, 50, 821828, Crossref

Koshlyakov, M. N., S. V. Gladyshev, R. Yu. Tarakanov, D. A. Fedorov (2011), Currents in the western Drake Passage according to the observations in January of 2010, Oceanology, 51, 187-198. Crossref 
Koshlyakov, M. N., S. V. Gladyshev, R. Yu. Tarakanov, D. A. Fedorov (2012), Currents in the Drake Passage based on the observations in November of 2010, Oceanology, 52, 299-308.Crossref

Koshlyakov, M. N., S. V. Gladyshev, R. Yu. Tarakanov, D. A. Fedorov (2013), Currents in the Drake Passage by the observations in October-November of 2011, Oceanology, 53, 1-12, Crossref

Kurnosova, M. O., K. V. Lebedev (2014), Study of transport variations in the Kuroshio extension system at $35^{\circ} \mathrm{N}, 147^{\circ} \mathrm{E}$ based on the data of Argo floats and satellite altimetry, Doklady Earth Sciences, 458, 1154-1157.Crossref

Lebedev, K. V. (1999), Average annual climate of the ocean. Part 2: Integral characteristics of the World Ocean climate (mass, heat, and salt transports), Izvestiya, Atmospheric and Oceanic Physics, 35, 87-96.

Lebedev, K. V. (2016), An argo-based model for investigation of the Global Ocean (AMIGO), Oceanology, 56, 172-181. Crossref

Lebedev, K. V., et al. (2010), Argo products at the Asia-Pacific Data-Research Center, Eos Trans. AGU, Ocean Sci. Meet. Suppl., Abstract IT25A-01, $91,26$.

Lebedev, K.V., A. S. Sarkisyan, O. P. Nikitin (2016), Comparative analysis of the North Atlantic surface circulation reproduced by three different methods, Izvestiya, Atmospheric and Oceanic Physics, 52, 410-417, Crossref

Renault, A., C. Provost, N. Sennéchael, N. Barré, A. Kartavtseff (2011), Two full-depth velocity sections in the Drake Passage in 2006 - Transport estimates, Deep-Sea Res. II, 58, 2572-2591,Crossref

Rio, M. H., S. Guinehut, G. Larnicol (2011), New CNES-CLS09 global mean dynamic topography computed from the combination of GRACE data, altimetry, and in situ measurements, J. Geophys. Res., 116, C07018 Crossref

Sarkisyan, AS., OP. Nikitin, K.V. Lebedev (2016), Physical characteristics of the Gulf Stream as an indicator of the quality of large-scale circulation modeling, Doklady Earth Sciences, 471, 1288-1291.Crossref

Tarakanov, R. Yu. (2012), The Scotia Sea and the Drake Passage as an orographic barrier for the Antarctic Circumpolar Current, Oceanology, 52, 157170, Crossref

Whitworth, T. (1983), Monitoring the transport of the Antarctic circumpolar current at Drake Passage, J. Phys. Oceanogr., 13, 2045-2057 Crossref

Whitworth, T., R. Peterson (1985), Volume transport of the Antarctic Circumpolar Current from bottom pressure measurements, J. Phys. Oceanogr., 15, 810-816 Crossref

K. V. Lebedev and R. Yu. Tarakanov, Shirshov Institute of Oceanology, Russian Academy of Sciences, 36 Nahimovskiy prospekt, 117997 Moscow, Russia. (KLebedev@ocean.ru) 